\title{
Uma Investigação Empírica sobre os Determinantes das Exportações Chinesas (1985-2005)
}

\section{An Empirical Investigation on China's Exports Determinants (1985-2005)}

\author{
Clésio Lourenço Xavier* \\ Samantha Ferreira e Cunha** \\ Flávio Vilela Vieira***
}

\begin{abstract}
Resumo: O presente artigo investigou a relação entre o IDE e as mudanças verificadas na pauta de exportações chinesa em direção aos setores de alta intensidade tecnológica. Estimou-se um modelo dos determinantes das exportações chinesas, considerando os efeitos diferenciados entre o IDE e os setores de exportação classificados segundo a intensidade tecnológica, através da análise de regressão de séries temporais e da estimação do modelo VAR com a análise de decomposição de variância. Os principais resultados mostraram que o "IDE" teve efeitos diferenciados entre os setores de exportação, sendo que sua importância é maior nos setores com maior conteúdo tecnológico. Além disso, outras variáveis explicativas utilizadas na estimação apresentaram resultados tão importantes quanto o "IDE", com destaque para a taxa de investimento da economia, o que é consoante com o desempenho econômico da China que apresenta uma taxa de crescimento média de $10 \%$ ao ano há mais de duas décadas.
\end{abstract}

Palavras-chave: China. Comércio exterior. Investimento direto estrangeiro. Tecnologia.

Abstract: The present study investigates the relationship between FDI and the changes verified in China's export structure towards high-tech sectors. It estimates a model of the determinants of Chinese exports performance, considering the different impacts of FDI on export structure classified according to its technological intensity, using time series variables, estimating a VAR model and the variance decomposition analysis. The main results suggested that FDI had different impacts among export sectors, which means that, FDI is more efficient in promoting exports from those sectors more technological-intensive. Besides that, other independent variables used in estimation seems to be as important as FDI, mainly the investment rate, which is consonant with China's economic performance that presents an average growth rate of $10 \%$ per year for at least two decades.

Keywords: China. International trade. Foreign direct investment.Technology.

JEL Classification: F14; C22; C32.

* Professor do Instituto de Economia da Universidade Federal de Uberlândia (IEUFU). Pesquisador e bolsista de produtividade do CNPq. E-mail: clesio@ie.ufu.br

** Doutoranda e pesquisadora do Núcleo de Economia Industrial e da Tecnologia (NEIT) do Instituto de Economia da Universidade Estadual de Campinas (Unicamp). E-mail: scunha@eco.unicamp.br

*** Professor do Instituto de Economia da Universidade Federal de Uberlândia (IEUFU). Pesquisador e bolsista de produtividade do CNPq. E-mail: flaviovieira@ufu.br 


\section{Introdução}

O presente artigo tem como tema as relações entre os fluxos de Investimento Direto Externo (IDE) e a sofisticação dos fluxos de exportações da China, a partir da segunda onda de reformas econômicas em 1993, que aprofundaram a integração da China à economia mundial. Nesse período, os fluxos de IDE começaram a ganhar relevância, o que se seguiu até os anos recentes.

Desde as reformas econômicas instauradas ao fim de 1970, quando a China transitou de uma economia fechada e planificada para uma economia aberta e mais orientada para o mercado, e considerando o aprofundamento do processo de integração da China à economia mundial em 1993, quando houve a ampliação das reformas econômicas, com redução gradativa das tarifas de comércio e a fixação da taxa de câmbio nominal em um nível que resulta em uma desvalorização real efetiva, dentre outros, são observadas expressivas taxas de crescimento econômico por quase três décadas, atingindo uma taxa média de $10 \%$ a.a. no período de 1980 até 2006. É a partir de meados dos anos 90, então, com a segunda onda de reformas, que o fluxo de investimento direto externo (IDE) e as exportações chinesas cresceram de maneira surpreendente, sugerindo uma provável relação entre o IDE e o comércio exterior, indiretamente, sobre o crescimento econômico. Ao mesmo tempo em que se verifica o aumento das exportações da China, identifica-se uma mudança na composição setorial de suas exportações em direção a setores de alta intensidade tecnológica, em detrimento dos setores intensivos em trabalho.

A literatura que trata das relações entre IDE, exportações e crescimento econômico na China sugere que a sofisticação da cesta de exportações em direção aos setores intensivos em capital e de alta produtividade é determinante do rápido crescimento econômico chinês e identifica uma relação causal positiva que pode ser bidirecional entre o fluxo de IDE e as exportações agregadas. Por outro lado, verifica-se que são raros os estudos que tratam dos efeitos do IDE sobre as exportações setoriais ou mesmo sobre os setores da economia, o que é uma negligência, já que os fluxos de IDE da China parecem estar concentrados nos setores de manufaturas mais intensivas em capital e tecnologia. Uma questão a ser investigada é se os fluxos de IDE são determinantes no processo de diversificação das exportações da China em direção a setores de alta tecnologia.

O trabalho está dividido em quatro seções: após esta introdução, a seção 2 apresenta uma revisão da literatura recente sobre o comércio exterior chinês e os fluxos de IDE na China. A seção 3 trata da análise econométrica, na qual são estimados os modelos dos determinantes das exportações, através da análise de séries temporais e o modelo de vetores autorregressivos (VAR). A última seção trata das considerações finais. 


\section{Revisão da Literatura Recente: Interação entre Comércio Exterior e Fluxo de Investimento Direto Externo na China no Período Recente}

O ritmo de expansão da participação da China no comércio mundial se acelerou com a ampliação das reformas econômicas em 1992, sendo que as exportações chinesas, em média, foram de 44 bilhões de dólares correntes, considerando o período de 1983 até 1992, aumentando para 270 bilhões de dólares, considerando o período de 1993 até 2004, representando um crescimento de 654\%, segundo dados do Banco Mundial. A evolução positiva do comércio exterior chinês foi acompanhada pelo ingresso crescente de investimento direto externo (IDE) sendo que no período de 1983-1992 a média dos fluxos de IDE foi de 3 bilhões de dólares correntes, e de 1993 até 2004, aumentou para 42 bilhões de dólares.

A expansão observada pode ser entendida, considerando-se o advento da abertura econômica, a partir de fatores que vão desde as características da própria economia chinesa, como os baixos custos de mão de obra e o tamanho e potencial do mercado de consumo interno que permite a exploração de economias de escala, até as políticas das reformas econômicas orientadas para o mercado.

\subsection{Interpretações sobre os Fluxos de Comércio Exterior da China}

As medidas de liberalização comercial aceleraram a expansão das atividades de processamento $^{1}$ internacional, o que foi determinante para a rápida diversificação das exportações de manufaturas. As atividades de processamento foram, inicialmente, atraídas para Zonas Especiais de Exportação ou Zonas Econômicas Especiais, áreas onde opera um regime fiscal diferenciado das demais empresas exportadoras do país, contemplando uma proteção efetiva. Os incentivos oferecidos pelo governo através das suas políticas de promoção das exportações estimularam a fragmentação da produção dos países vizinhos asiáticos que foram atraídos pelos baixos custos de mão de obra.

No início dos anos 1990, o setor de manufatura leve representava mais de $40 \%$ das exportações da China (calçados, vestuário, brinquedos e outros). Ao longo da década, a China obteve ganhos substanciais em outros setores mais sofisticados e a proporção das exportações chinesas representadas por máquinas e transporte (incluindo eletrônicos) aumentou de 17\%, em 1993, para 41\% em 2003, enquanto a proporção dos artigos manufaturados leves declinou de $42 \%$ para 28\% (RUMBAUGH; BLANCHER, 2004). O mesmo é observado para o setor de produtos primários (alimentos, produtos agrícolas e combustíveis minerais)

1 Também denominadas "exportações de processamento" e "re-exportações", referem-se ao processamento de produtos intermediários importados para a exportação de produtos finais. 
cuja participação no total das exportações reduziu-se de quase 50\%, em 1980, para menos de 10\% em 2002 (LUNDVALL; GU, 2006).

O segundo fenômeno que envolve a ascensão da China no mercado internacional, além da expansão de suas exportações e sua diversificação em direção aos setores de maior conteúdo tecnológico, é a diversificação de seus parceiros comerciais. Rumbaugh e Blancher (2004) destacam que o superávit comercial com os Estados Unidos e a Europa aumentou significativamente no período 1997-2002, ao mesmo tempo que ampliou o déficit com a região asiática. O crescimento do market-share da China no mercado dos Estados Unidos e da Europa está relacionado, então, com a mudança da estrutura de suas exportações em direção aos maquinários, telecomunicações e bens de consumo eletrônicos e equipamentos de informática. Por outro lado, o déficit com os mercados em desenvolvimento refletem o crescimento da demanda chinesa por commodities primárias (como óleo cru e cobre), bens intermediários (componentes de produtos eletrônicos e outros bens de consumo duráveis) e bens de capital (EICHENGREEN; RHEE; TONG, 2004).

Sobre as perspectivas futuras da China e uma avaliação das possibilidades de uma maior especialização chinesa em produtos sofisticados competindo com os mesmos produtos comercializados pelos países de alta renda, Rodrik (2006) chama a atenção para a capacidade da China de ampliar ainda mais suas exportações em setores mais sofisticados. Enquanto as exportações dos setores intensivos em trabalho sempre tiveram papel importante na cesta de exportações chinesa, a China também exporta uma grande variedade de produtos, a despeito do seu baixo nível de renda per capita, exportando nos setores em que os países ricos exportam. O autor constatou uma relação positiva entre o nível de produtividade das exportações da China e o seu nível de renda (crescimento). O argumento é o de que os investidores de outros setores são atraídos para aqueles setores de maior produtividade, expandindoos e deslocando os recursos da economia das atividades de baixa produtividade para as de mais alta, caracterizando um processo de difusão da produtividade dentro da economia.

\subsection{A Importância dos Fluxos de Investimento Direto Externo na Economia Chinesa}

Os fluxos de IDE mundiais apresentaram um ritmo de crescimento superior ao das exportações mundiais no período 1986-1990 e 1996-2000. A razão é a maior abertura comercial e financeira e, consequentemente, o relaxamento das restrições sobre o capital estrangeiro. Mais recentemente, em meados de 90, essa aceleração se explica pelas fusões e aquisições que ocorreram nos países da América Latina sob a égide dos programas de liberalização econômica. A importância do IDE e do comércio exterior para o crescimento econômico 
pode ser medida pela razão entre o fluxo de IDE, as exportações e o produto interno bruto (PIB) da China. Os dados mostram que essa importância cresceu significativamente nos últimos anos. Em 1994, a participação do fluxo de IDE sobre o PIB era de 4\%, já em 2004 essa participação foi de 8\%. O mesmo é observado em relação às exportações, em 1994 a razão entre as exportações e o PIB foi de 16,5\%, passando a 38\% em 2004, segundo dados do Banco Mundial.

As estratégias de IDE que entraram na China são baseadas em marketseeking e efficiency-seeking, através das quais, buscam ter acesso ao seu grande mercado consumidor potencial para oferecer seus produtos e serviços, bem como, explorar as vantagens locais de baixos custos da mão de obra em determinadas etapas da cadeia produtiva, dessa maneira, reduzindo custos e gerando economias de escala. Diante da ideia de um novo paradigma do crescimento orientado para as exportações e "puxado" pelo IDE, as multinacionais têm um papel cada vez maior no desenvolvimento dessas economias. De acordo com Asian Development Outlook (2004), o desempenho exportador das economias em desenvolvimento a partir dos anos 1970 e meados dos anos 1980, esteve fortemente associado à presença das multinacionais. A participação das multinacionais no total das exportações de manufaturas dos países em desenvolvimento era de $24 \%$, em 1980, e aumentou para $36 \%$ em 1990.

Zucoloto e Cassiolato (2006) chamam a atenção para os limitados efeitos de transbordamento (positivo) advindo da presença do investidor estrangeiro. Sua argumentação aponta que a realização de gastos em pesquisa e desenvolvimento (PED) por multinacionais nas economias em desenvolvimento é pequena no montante e modesta em complexidade e não estimula, em geral, o desenvolvimento de novos produtos e processos, e que as firmas domésticas acabaram adotando um comportamento mais imitativo (das multinacionais) do que inovador. Por outro lado, observando os casos da China e Índia, os autores levantam as características diferenciadas do padrão de atração de empresas multinacionais desses países quando comparado ao caso brasileiro, em que não se viu ocorrer evoluções positivas nos gastos em PEBD e na capacitação tecnológica. Trata-se da seletividade do investimento externo, da aprovação de joint ventures prioritariamente em setores de alta tecnologia, exigindo sua transferência.

A despeito do significativo grau de abertura econômica alcançado pela China antes da sua entrada na Organização Mundial do Comércio OMC, esta representou um importante marco no aprofundamento das reformas de liberalização da economia, sendo que o destaque são as políticas de estímulo ao setor externo associadas à atração de investimentos estrangeiros.

A literatura apontou que as políticas de promoção do comércio exterior praticadas na China conformavam um regime comercial "dual", pois o segmento das atividades de processamento era aberto ao comércio internacional e à 
entrada de investimentos estrangeiros, enquanto o segmento doméstico correspondente às demais atividades de exportações era fortemente regulado, restringindo a participação das firmas no comércio exterior, e protegido contra a competição estrangeira. Todavia, Branstetter e Lardy (2006) argumentam que, na segunda metade dos anos 1990, foi observada uma redução desse caráter dual do regime comercial, o que se revelou no aumento mais que proporcional das importações que não possuem privilégios tarifários sobre aquelas importações de partes e componentes com isenção de tarifas. Um último importante aspecto da política comercial diz respeito às mudanças promovidas na taxa de câmbio. Antes da reforma, o governo mantinha uma taxa de câmbio valorizada que favorecia a importação de bens de capital necessários para o desenvolvimento da indústria pesada. Durante a reforma, o governo promoveu a desvalorização da moeda chinesa em etapas. A taxa de câmbio era de Yuan/US\$=1,5 em 1981, passando a ser de Yuan/US $\$=8,7$ em 1994, e fixada em Yuan/US $\$=8,28$ até 2005 , com impactos favoráveis à competitividade das exportações chinesas ${ }^{2}$ (BRANSTETTER; LARDY, 2006).

\subsection{Uma Revisão dos Estudos Empíricos Recentes sobre as Relações entre IDE e Exportações}

A análise enfatiza os efeitos dos fluxos de IDE sobre o desempenho das exportações dos países receptores, dada a importância dessas variáveis (exportações e IDE) na explicação do extraordinário crescimento econômico observado nas economias asiáticas. Hsiao e Hsiao (2006) buscam investigar as relações de causalidade entre IDE, exportações e PIB (como proxy para o crescimento econômico) para oito economias asiáticas, compreendendo os anos de 1986 até 2004, que corresponde à fase dinâmica coincidente entre os países da amostra. Os autores estimaram um modelo VAR (autorregressivo vetorial) para analisar relações de causalidade de Granger entre as variáveis PIB, exportações e IDE. Foram estimados dados em painel agrupando as oito economias e analisando para causalidade de Granger do grupo. Observou-se que, em geral, os fluxos de IDE têm impactos positivos diretos sobre o Produto Interno Bruto (PIB) e indiretos através das exportações, que, por sua vez, têm relação com o PIB.

Johnson (2006) chama a atenção para a importância que os fluxos de IDE e o comércio exterior tiveram no crescimento econômico da região do Leste Asiático e propõe investigar a relação entre IDE e exportações para China, Hong Kong, Indonésia, Coreia, Malásia, Cingapura, Taiwan e Tailândia. Observando os valores de IDE e exportações per capita para as oito economias selecionadas nos anos de 1980 e 2003, destacou-se o aumento significativo dessa proporção durante o período em todas as economias, indicando a importância crescente

$2 \quad$ A moeda da China denomina-se Renminbi (RMB), e a unidade da moeda denomina-se Yuan. De acordo com o relatório da Organização Mundial do Comércio (2006), em julho de 2005 o governou anunciou uma revalorização do RMB em relação ao dólar em $2.1 \%$ e mudanças no regime cambial em direção a um regime mais flexível. Desde as mudanças anunciadas, a taxa de câmbio nominal efetiva valorizou-se em cerca de $5 \%$. 
desses fluxos. Os resultados parecem sugerir que os fluxos de IDE que entram no país tendem a aumentar as exportações, enquanto os fluxos de IDE que saem das economias aparecem com sinal positivo e negativo, sugerindo relações de complementaridade e substituição. Com o objetivo de aumentar o número de observações, a análise é feita para os dados em painel com efeitos fixos, e os resultados apontaram para um efeito positivo e significativo dos fluxos de IDE que entram nos países sobre as exportações, enquanto os resultados para os fluxos de saída de IDE não se mostraram significativos.

Zhang e Felminghan (2001) analisam as relações causais entre fluxos de IDE e exportações da China e de suas províncias no período de 1986 até 1999. A abordagem no nível provincial se baseia na constatação de diferenças entre as regiões da China quanto à entrada de IDE, o que está relacionado com a proximidade à costa marítima e aos principais países de origem do IDE, como Hong Kong. A desigualdade na distribuição dos fluxos de IDE sugere diferenças entre as regiões quanto à interação entre exportações e IDE. Através da análise das estatísticas descritivas, é possível perceber que nas províncias que receberam alto volume de IDE, a taxa de crescimento das exportações foi maior, o que evidencia a precedência do IDE sobre as exportações nesse grupo de províncias. Os resultados econométricos confirmaram a expectativa de diferenças nas relações entre IDE e as exportações entre as províncias que receberam montantes diferentes de IDE no período de análise.

Liu, Wang e Wei (2001) investigam relações de causalidade entre o IDE e o comércio exterior na China no período 1984-1998 com base em dados de painel relativos aos fluxos bilaterais de comércio entre a China e países/regiões selecionados. Os resultados mostraram que variações nas importações causam, no sentido Granger, variações no IDE do país de origem, em que o sinal positivo dos coeficientes estimados indica uma relação de complementaridade entre as variáveis. Uma segunda conclusão emerge da relação entre IDE e exportações, em que o IDE causa, no sentido Granger, as exportações, o que deve estar associado ao comércio complementar gerado a partir de países que possuem diferentes intensidades de fatores; nesse sentido, o IDE que entra na China é atraído pelos baixos custos do fator trabalho. Os autores consideram que os resultados obtidos indicam a ocorrência de um ciclo virtuoso, no qual o crescimento das importações do país estrangeiro para o mercado chinês leva ao aumento dos fluxos de IDE originados em tal país; o IDE, por sua vez, leva ao aumento das exportações, e o crescimento das exportações gera um aumento das importações.

O estudo de Zhang e Song (2000) chama a atenção para a importância crescente da China como receptor de IDE entre as economias em desenvolvimento, ao mesmo tempo que sua participação nas exportações mundiais cresceu de $0.75 \%$ em 1978 para 3.3\% em 1997, sendo que a participação das firmas estrangeiras no total das exportações aumentou de $20 \%$, na década de 1980, para 41\% em 1997.O modelo estima uma regressão múltipla 
para dados de painel em nível das províncias, na qual as exportações são uma função do IDE do período anterior, das próprias exportações defasadas no tempo, do investimento doméstico defasado, da taxa de crescimento do PIB, da participação do setor de manufaturados em relação ao PIB, e, por fim, é incluída uma variável de câmbio. Utilizando os métodos de efeitos aleatórios e mínimos quadrados generalizados, encontrou-se um efeito positivo e significativo do IDE defasado sobre o desempenho das exportações correntes, sendo a variável estatisticamente mais significativa.

Zhang (2005), com base na importância teórica do IDE para promoção das exportações, chama a atenção para o caso especial da China, onde o boom das exportações foi acompanhado por um aumento significativo dos fluxos de IDE no país, buscando desenvolver o tema da relação entre o IDE e as exportações a partir de uma abordagem empírica. O seu estudo, ao tratar a relação entre o IDE e as exportações para 186 indústrias, inova ao subdividir a amostra entre as indústrias intensivas em capital e as indústrias intensivas em trabalho. $\mathrm{O}$ autor considera as exportações em função do IDE, do capital doméstico, dos salários, das economias de escala e uma variável dummy para diferenciar as indústrias quanto à intensidade dos fatores (capital e trabalho). Os resultados mostraram que, de uma maneira geral, os modelos especificados são bastante satisfatórios, sendo que a variável IDE parece ser a mais influente sobre as exportações, com coeficientes maiores e estatisticamente mais significativos. Além disso, os efeitos do IDE sobre a indústria intensiva em trabalho é relativamente maior do que a indústria intensiva em capital.

\section{Análise de Séries Temporais: Estacionariedade e Modelos VAR}

Para examinar a influência do investimento direto externo sobre o desempenho exportador, utilizou-se o instrumental econométrico das séries temporais, particularmente, a análise de regressão envolvendo dados de séries temporais e a metodologia dos vetores autorregressivos (VAR), com a análise de decomposição de variância.

O modelo VAR envolve duas escolhas importantes: quais variáveis econômicas a serem incluídas no modelo e qual o número de defasagens. Em um primeiro momento, seriam incluídas todas as variáveis que têm efeitos econômicos importantes em suas relações de interdependência. Mas, a inclusão de variáveis é limitada pelo número de observações, pois se perdem graus de liberdade. Para escolha do número de defasagens, são utilizados testes apropriados. Se o modelo considera muitas defasagens, os graus de liberdade são reduzidos. De outro lado, se o número de defasagens é pequeno, o modelo é mal especificado. Assim, deve-se considerar, inicialmente, a defasagem máxima plausível, dados os graus de liberdade. 
Portanto, para análise do VAR, torna-se importante considerar os critérios de seleção. No presente estudo, foram utilizados os testes AIC (Akaike Information Criterion) e o SBC (Schwarz Criterion). Inicialmente, procurou-se estimar o impacto do IDE sobre o total das exportações, segundo a especificação a seguir:

$$
X_{t}=\beta_{0}+\beta_{1} I D E_{t}+\beta_{2}(C O N T R O L E S)+v_{t}
$$

Todas as variáveis são de frequência anual e compreendem o período 19852005. A equação (1) se refere ao modelo mais geral estimado para as exportações totais da China e inclui, além do IDE, outras variáveis explicativas, que podem também ser denominadas "variáveis de controle". A partir do modelo mais geral, outras especificações foram consideradas, partindo-se de combinações diferentes das variáveis explicativas, com o objetivo de testar a robustez dos resultados e corrigir para problemas de multicolinearidade e correlação serial. A descrição das variáveis utilizadas nas estimativas é feita a seguir:

$X_{t}=$ Exportações totais da China em dólares correntes.

Variáveis de controle:

$I D E_{t}=$ Estoque de IDE em dólares correntes.

$X_{t-1}=$ Exportações defasadas no tempo.

$T X I_{t}=$ Taxa de investimento medida pela razão entre a Formação Bruta de Capital Fixo (FBCF) e o Produto Interno Bruto (PIB). Ambos expressos em dólares correntes.

$T C R E F_{t}=$ Taxa de câmbio real efetiva com ano base em 2000.

$G A_{t}=$ Grau de abertura da economia medido pela razão entre a corrente de comércio (Exportações e Importações) e o PIB.

PIB MUNDO = Taxa de crescimento anual do PIB mundial.

PIB UE = Taxa de crescimento anual do PIB da União Europeia.

Foi considerado o estoque de IDE em vez dos fluxos, pois permite captar os efeitos cumulativos e de mais longo prazo característicos desses investimentos. Espera-se um coeficiente positivo no caso do IDE. Tais efeitos positivos sobre as exportações, como já discutido anteriormente, se devem à transferência de tecnologia, e técnicas gerenciais mais avançadas introduzidas pelas firmas multinacionais e seu melhor acesso aos mercados globais. Em relação à variável $E X P_{t-1}$, esta representa a relação entre o desempenho exportador passado e 
futuro, sendo que um aumento das exportações no período passado sugere um aumento das exportações no próximo ano, espera-se, então, um coeficiente positivo. A variável TXI indica a importância dos investimentos em capital físico para todos os setores da economia, induzindo a ganhos de produtividade que tendem a aumentar a capacidade de exportar do país, também nesse caso espera-se um coeficiente positivo. A variável TCREF capta a influência dos preços relativos sobre a competitividade das exportações. Ao considerar a taxa de câmbio real efetiva está se buscando a variabilidade das observações, uma vez que a taxa de câmbio nominal da China é fixada em um nível subvalorizado. Um aumento de TCREF $F_{t}$ significa que a moeda da China se desvalorizou em relação às demais, ampliando a competitividade das exportações, portanto, espera-se um coeficiente positivo. A variável $G A_{t}$ permite captar os efeitos da liberalização comercial sobre as exportações. Considerando a importância da abertura econômica sobre o processo de expansão comercial da China e atração de fluxos de IDE, espera-se que um aumento do grau de abertura tenha um impacto positivo sobre as exportações. Por fim, as variáveis PIB Mundo e PIB UE permitem captar o efeito das variações da renda externa sobre as exportações. Ao considerar também a economia da União Europeia separadamente, buscouse captar a influência de um dos principais parceiros comerciais da China. Espera-se, portanto, um coeficiente positivo no caso dessas variáveis.

Além da estimação de um modelo sobre o impacto do IDE no total das exportações da China, testou-se a hipótese de que os efeitos do IDE se diferenciam entre os setores de exportação de manufaturas de alta, média e baixa tecnologia. Com isso, buscou-se estabelecer uma interação entre o IDE e as mudanças na composição da pauta de exportações da China em direção aos setores de mais alta tecnologia, em detrimento das manufaturas leves mais intensivas em trabalho. O modelo que trata dos impactos do IDE por setor de exportação tem a seguinte especificação:

$$
X_{t i}=\beta_{0}+\beta_{1} I D E_{t}+\beta_{2}(C O N T R O L E S)+v_{t i}
$$

Como no caso do modelo mais geral, as variáveis são de frequência anual e se referem ao período 1985-2005. Por conta da indisponibilidade de dados, não foi possível considerar as variáveis de controle por setor, à exceção da variável "exportações defasadas", pois apenas a variável dependente "exportações" possui dados setoriais. As novas variáveis, incluindo cada uma corrente e com uma defasagem, utilizadas nas estimativas por setor são descritas da seguinte forma:

$X L T=$ Exportações dos setores de baixa tecnologia em dólares correntes.

$X M T=$ Exportações dos setores de média tecnologia em dólares correntes.

$X H T=$ Exportações dos setores de alta tecnologia em dólares correntes. 
No caso das exportações setoriais, a interpretação dos coeficientes não é diferente do modelo mais geral; então, em todos os casos, espera-se encontrar coeficientes positivos. Em relação à variável IDE, testa-se a hipótese de efeitos diferenciados entre os setores, mas espera-se encontrar diferenças nas magnitudes do coeficiente, mais do que um sinal negativo.

\subsection{Teste de Raiz Unitária e Escolha das Defasagens do Modelo VAR}

A Tabela 1 apresenta os resultados do teste ADF para as variáveis utilizadas na análise de regressão. Os valores do $\mathrm{t}$ - ADF mostrados na tabela se referem àqueles em que as variáveis foram consideradas estacionárias; além da estatística $\mathrm{t}$ - ADF, observou-se o $p$-value para rejeitar a hipótese nula de que a série tem uma raiz unitária. Foi estimado um modelo log-linear, captando a elasticidade das exportações em relação às variáveis consideradas. Todas as variáveis se mostraram estacionárias em nível, à exceção da taxa de crescimento anual do PIB mundial, que se mostrou estacionária em primeira diferença ou I(1).

Tabela 1 - Testes de raiz unitária - ADF - China (1985-2005)

\begin{tabular}{c|c|c|c|c|c|c|c}
\hline Variável & Defasagem & Constante & Tendência & t-ADF & p-value & & $\begin{array}{c}\text { Ordem de } \\
\text { Integração }\end{array}$ \\
\hline $\log (\mathrm{X})$ & 5 & SIM & SIM & -3.71888 & 0.0535 & $*$ & $\mathrm{I}(0)$ \\
\hline $\log (\mathrm{IDE})$ & 8 & SIM & NÃO & -4.73418 & 0.0038 & $* *$ & $\mathrm{I}(0)$ \\
\hline $\log (\mathrm{TXI})$ & 5 & SIM & SIM & -4.4672 & 0.0155 & $* *$ & $\mathrm{I}(0)$ \\
\hline $\log (\mathrm{TCREF})$ & 6 & SIM & NÃO & -3.20008 & 0.0419 & $* *$ & $\mathrm{I}(0)$ \\
\hline $\log (\mathrm{GA})$ & 0 & NÃO & NÃO & -2.74547 & 0.0087 & $* *$ & $\mathrm{I}(0)$ \\
\hline DPIB Mundo & 0 & NÃO & NÃO & -4.9537 & 0.0000 & $* * *$ & $\mathrm{I}(1)$ \\
\hline $\log (\mathrm{XHT})$ & 8 & SIM & SIM & -20.2321 & 0.0001 & $* * *$ & $\mathrm{I}(0)$ \\
\hline $\log (\mathrm{XMT})$ & 8 & SIM & SIM & -4.60352 & 0.0174 & $* *$ & $\mathrm{I}(0)$ \\
\hline $\log (\mathrm{XLT})$ & 8 & SIM & SIM & -3.92244 & 0.0469 & $* *$ & $\mathrm{I}(0)$ \\
\hline $\log (\mathrm{Xt}-1)$ & 5 & SIM & SIM & -3.455978 & 0.0843 & $* * *$ & $\mathrm{I}(0)$ \\
\hline
\end{tabular}

Fonte: Elaborada pelos autores a partir dos dados da pesquisa.

Nota: ${ }^{*}, * *, * * *$, significativo a $10 \%, 5 \%$ e $1 \%$.

Após testar a estacionaridade das séries, o próximo passo foi escolher a ordem de defasagem do modelo VAR, com base no critério de Akaike (AC) e Schwarz (SC). A partir da utilização das variáveis estacionárias em nível, primeira diferença (D) ou segunda diferença (DD), foram estimados modelos distintos, conforme a seguinte descrição:

Exportações Totais:

Modelo $1=\mathrm{X}$, IDE, TXI, TCREF, GA 
Modelo 2 $=$ X, IDE, TXI, TCREF, PIBMUNDO

Modelo $3=\mathrm{X}$, IDE, TXI, TCREF, PIBUE

Exportações por setor ${ }^{3}$ :

Modelo $1=$ XHT, IDE, TXI, TCREF, GA

Modelo $2=$ XHT, IDE, TXI, TCREF, PIBMUNDO

Modelo $3=$ XHT, IDE, TXI, TCREF, PIBUE

As Tabelas 2 e 3 apresentam os valores do critério de informação utilizado para escolha da ordem de defasagem do VAR para os três modelos das exportações totais e os três modelos das exportações por setor. Dado o número de observações, partiu-se de um modelo com duas defasagens até uma defasagem, sendo que, em todos os casos, o modelo com 1 defasagem apresentou os menores valores, principalmente, para o teste (SC).

Tabela 2 - Ordem de defasagens do VAR para a China - Exportações totais (1985-2005)

\begin{tabular}{c|c|c|c}
\hline \multicolumn{4}{c}{ Schwarz (SC) } \\
\hline Defasagens & Modelo 1 & Modelo 2 & Modelo 3 \\
\hline $\begin{array}{c}\text { Sistema com 2 } \\
\text { defasagens }\end{array}$ & 98.40548 & 106.6692 & 107.0871 \\
\hline $\begin{array}{c}\text { Sistema com 1 } \\
\text { defasagem }\end{array}$ & $\mathbf{9 6 . 7 1 2 6 4}$ & $\mathbf{1 0 4 . 3 8 6 6}$ & $\mathbf{1 0 4 . 6 6 5 7}$ \\
\hline
\end{tabular}

Fonte: Elaborada pelos autores a partir dos dados da pesquisa.

Tabela 3 - Ordem de defasagens do VAR para a China - Exportações por setor (1985-2005)

\begin{tabular}{c|c|c|c|c}
\hline & & \multicolumn{3}{|c}{ Schwarz SC } \\
\hline $\begin{array}{c}\text { Exportações/ } \\
\text { Modelos }\end{array}$ & Defasagens & Modelo 1 & Modelo 2 & Modelo 3 \\
\hline Alta-tecnologia & Sistema com 2 defasagens & 57.52742 & 63.44107 & 64.16555 \\
\hline & Sistema com 1 defasagem & $\mathbf{5 4 . 8 4 5 0 1}$ & $\mathbf{6 1 . 5 5 6 8 2}$ & $\mathbf{6 1 . 4 6 6 1 4}$ \\
\hline $\begin{array}{c}\text { Média- } \\
\text { tecnologia }\end{array}$ & Sistema com 2 defasagens & 56.42436 & 61.26885 & 62.0783 \\
\hline & Sistema com 1 defasagem & $\mathbf{5 4 . 0 2 1 3 3}$ & $\mathbf{5 9 . 9 3 0 9 1}$ & $\mathbf{5 9 . 8 6 3 9 6}$ \\
\hline Baixa-tecnologia & Sistema com 2 defasagens & 57.90553 & 63.3541 & 63.21835 \\
\hline & Sistema com 1 defasagem & $\mathbf{5 5 . 6 9 4 2 1}$ & $\mathbf{6 1 . 9 8 3 6 5}$ & $\mathbf{6 1 . 4 6 3 6 4}$ \\
\hline
\end{tabular}

Fonte: Elaborada pelos autores a partir dos dados da pesquisa.

3 Os modelos são os mesmos no caso do setor de baixa tecnologia (XLT) e média tecnologia (XMT), pois as variáveis explicativas não são tratadas setorialmente, conforme já explicitado. 


\subsection{Análise de Regressão Múltipla para Exportações da China}

A Tabela 4 apresenta os resultados da estimação do modelo mais geral conforme a equação (1), que considera as exportações totais como variável dependente. Observando o modelo 1, foram encontrados resultados interessantes, pois os coeficientes das variáveis se mostraram significativos a $1 \%$, com sinais esperados, à exceção da variável taxa de investimento; ademais, os valores dos testes BG LM ${ }^{4}$ e White não rejeitaram a hipótese nula de ausência de correlação serial e ausência de heterocedasticidade ou erro de especificação. Apesar de a variável IDE ter apresentado um resultado positivo em termos de seu impacto sobre as exportações, a taxa de câmbio e o grau de abertura apresentaram coeficientes positivos maiores. Em relação à taxa de investimento doméstico, o sinal inesperado pode estar relacionado ao problema de multicolinearidade entre essa variável e o IDE, uma vez que os dados de FBCF não separam para a origem dos investimentos. Mas a regressão auxiliar estimada entre as duas variáveis explicativas apresentou um $R_{2}$ de 0.54 , o que apontaria para uma colinearidade não perfeita, o que significa que os estimadores por MQO ainda são os MELNV. ${ }^{5}$

Tabela 4 - Exportações Totais - Variável dependente - Logaritmo das exportações (1985-2005)

\begin{tabular}{|c|c|c|c|c|c|c|c|}
\hline & (1) & (2) & (3) & (4) & (5) & (6) & (7) \\
\hline \multirow[t]{2}{*}{$\log (\mathrm{IDE})$} & 0.4493 & 0.4500 & & & -0.0909 & -0.0921 & \\
\hline & $(0.0000)^{* * *}$ & $(0.0000)^{* * *}$ & & & $(0.1572)$ & $(0.1295)$ & \\
\hline \multirow[t]{2}{*}{$\log (\mathrm{TXI})$} & -0.6439 & & -0.6866 & -0.0499 & 0.0237 & & 0.1071 \\
\hline & $(0.0616)^{*}$ & & $(0.5291)$ & $(0.8380)$ & $(0.9286)$ & & $(0.6912)$ \\
\hline \multirow[t]{2}{*}{ Log(TCREF) } & 1.0777 & 1.0245 & 1.128165 & 0.1653 & -0.1816 & -0.1860 & -0.0848 \\
\hline & $(0.0000)^{* * *}$ & $(0.0000)^{* * *}$ & $(0.0187)^{* *}$ & $(0.2737)$ & $(0.2353)$ & $(0.1851)$ & $(0.5441)$ \\
\hline \multirow[t]{2}{*}{$\log (\mathrm{GA})$} & 2.1699 & 1.9090 & 3.901091 & 0.6975 & & & \\
\hline & $(0.0000) * * *$ & $(0.0000) * * *$ & $(0.0000) * * *$ & $(0.0048)^{* *}$ & & & \\
\hline \multirow[t]{2}{*}{$\log (X t-1)$} & & & & 0.848084 & 1.1221 & 1.1258 & 1.0064 \\
\hline & & & & $(0.0000)^{* * *}$ & $(0.0000)^{* * *}$ & $(0.0000)^{* * *}$ & $(0.0000)^{* * *}$ \\
\hline \multirow[t]{2}{*}{ DPIB Mundo } & & & & & 0.0490 & 0.0498 & 0.0451 \\
\hline & & & & & $(0.0310)^{* *}$ & $(0.0123)^{* *}$ & $(0.0492)^{* * *}$ \\
\hline Observações & 21 & 21 & 21 & 20 & 20 & 20 & 20 \\
\hline $\mathrm{R} 2$ & 0.9929 & 0.9911 & 0.9161 & 0.9960 & 0.995383 & 0.995383 & 0.99465 \\
\hline \multirow[t]{2}{*}{ Teste BG LM } & 3.1752 & 1.0392 & 9.8846 & 3.3548 & 4.9638 & 4.8433 & 1.2585 \\
\hline & $(0.2044)$ & $(0.5947)$ & $(0.0071)^{* *}$ & $(0.1868)$ & $(0.0835)^{* * *}$ & $(0.0887)^{* * *}$ & $(0.5329)$ \\
\hline \multirow[t]{2}{*}{ Teste de White } & 17.8026 & 11.3117 & 11.0155 & 19.1763 & 12.3787 & 11.65972 & 11.82981 \\
\hline & $(0.2159)$ & $(0.2549)$ & $(0.2746)$ & $(0.1580)$ & $(0.2605)$ & $(0.1670)$ & (0.6199) \\
\hline
\end{tabular}

Fonte: Elaborada pelos autores a partir dos dados da pesquisa.

Nota: Todas as regressões incluem um termo constante e são estimadas por MQO. P-values estão em parênteses $\left(* * *, * *\right.$, ${ }^{*}$ significativo a $1 \%, 5 \%$ e $\left.10 \%\right)$.

4 Teste LM de Breusch-Godfrey para detectar a presença de correlação serial. O teste de White detecta a presença de heterocedasticidade.

5 Melhores estimadores lineares não viesados. 
Dada a suspeita de colinearidade não perfeita, o modelo foi estimado com a exclusão da variável taxa de investimento (TXI), como pode ser visto na coluna (2), obtendo resultados robustos ao nível de $1 \%$ de significância. O modelo na coluna (3) excluiu, agora, o IDE e manteve a taxa de investimento, mas os resultados dessa variável se mostraram não significativos; além disso, os testes BG LM apontaram para um problema de correlação serial dos erros. Para corrigir tal problema, optou-se por incluir a variável $X_{t-1}$ exportações defasadas no tempo, como pode ser observado na coluna (4). A inclusão dessa variável corrigiu o problema de correlação serial, todavia, o coeficiente da variável TXI permaneceu não significativo, além disso, a taxa de câmbio real efetiva deixou de ser significativa. Apenas as variáveis GA e $X_{t-1}$ se mostraram significativas, com os sinais esperados, o que dá uma pista sobre a importância da variável $X_{t-1}$ no modelo de determinação das exportações chinesas.

As colunas (5), (6) e (7) apresentam os resultados do modelo estimado para as exportações com uma nova especificação: a inclusão da variável PIB Mundo e a exclusão da variável GA. A estimação do modelo sem a variável GA deve-se ao fato de que esta apresentou problemas de colinearidade não perfeita. Uma proxy para captar a influência do grau de abertura sobre as exportações poderia ser as barreiras comerciais impostas pelos parceiros comerciais da China, mas, em razão das dificuldades para acessar tais dados, optou-se por estimar um novo modelo incluindo uma nova variável explicativa que, no caso, foi a taxa de crescimento do PIB mundial. ${ }^{6}$

Observando a coluna (5), que inclui a variável $X_{t-1}$ para corrigir problema de correlação serial dos erros, observa-se que tal variável mostrou um resultado positivo e significativo, assim como o PIB Mundo. Todavia, as demais variáveis se mostraram não significativas, isso pode ser explicado pela predominância da variável $X_{t-1}$ sobre as demais, já que esta apresentou um coeficiente bastante alto. Esse problema foi levantado por Zhang e Song (2001) em sua estimação dos determinantes das exportações da China.

As colunas (6) e (7) testa a robustez dos resultados, dada a suspeita de multicolinearidade entre IDE e TXI, com a estimação de um modelo que exclui a variável TXI e outro que exclui o IDE. Os resultados não divergem do que foi encontrado na coluna (5), o que parece indicar que os resultados não significativos dessas variáveis (IDE e TXI) não se devem à suspeita de multicolinearidade, sendo que apenas as variáveis $X_{t-1}$ e PIB mundo se mostraram significativas e com sinais esperados.

\footnotetext{
6 Na verdade, um modelo geral dos determinantes das exportações deveria levar em conta os impactos do grau de abertura e da renda externa, mas, por conta do baixo número de observações e sabendo que a inclusão de mais uma variável ao modelo reduziria os graus de liberdade, essa possibilidade foi desconsiderada.
} 
A Tabela 5 apresenta os resultados das estimativas para as exportações de baixa tecnologia. O modelo da coluna (1) considerou como variáveis explicativas: investimento direto externo (IDE), taxa de investimento (TXI), taxa de câmbio real efetiva (TCREF) e grau de abertura (GA). As variáveis, em geral, apresentaram resultados significativos e com sinais esperados, à exceção mais uma vez da variável TXI, bem como da taxa de câmbio. Além disso, os valores críticos dos testes BG LM e White não rejeitaram a hipótese nula de ausência de correlação serial e heterocedasticidade. Observando, então, a variável IDE, pode-se dizer que o seu coeficiente é maior do que no mesmo modelo estimado para as exportações totais (0.61 contra 0.44), mas é interessante comparar esse resultado com os obtidos para os demais setores, o que será feito adiante.

As colunas (2) e (3) estimam dois modelos testando, em separado, os efeitos do IDE e da taxa de investimento. Por causa dos valores do teste de BG LM, que indicaram a presença de correlação serial, foram apresentados apenas os resultados das estimações que incluíram a variável $X L T_{t-1}$ para corrigir o problema. Pode-se dizer que, como observado no caso das estimações das exportações totais, a variável $X L T_{t-1}$ apresenta um coeficiente positivo esignificativo, enquanto as demais variáveis deixam de ser significativas, certamente porque ela predomina sobre as demais.

As colunas de (4) a (7) se referem às estimações que incluem a variável PIB Mundo, excluindo a variável grau de abertura. Na coluna (4) é possível perceber que, com a inclusão de PIB Mundo, apenas as variáveis IDE e a TCREF apresentam um resultado significativo, sendo que o coeficiente do IDE aumentou para 0.71 ao nível de $1 \%$ de significância, confirmando, então, a suspeita de colinearidade pelo grau de abertura sobre essa variável. A coluna (5) inclui a variável $X L T_{t-1}$ para tentar corrigir o problema de correlação serial positiva (estatística Durbin-Watson menor que 2), mas os resultados não se alteram, sendo que apenas a variável incluída mostrou-se significativa. As colunas (6) e (7) reportam as estimações para o modelo que exclui TXI e outro que exclui IDE, com a inclusão de XLT $T_{t-1}$, pelos mesmos motivos já expostos. Apenas os os resultados de $X L T_{t-1}$ se mostraram significativos. De maneira geral, pode-se dizer que a especificação que incluiu a variável PIB Mundo não apresentou resultados satisfatórios. 
Tabela 5 - Exportações de baixa tecnologia - Variável dependente - Logaritmo das exportações de baixa tecnologia (1985-2005)

\begin{tabular}{|c|c|c|c|c|c|c|c|}
\hline & (1) & (2) & (3) & (4) & (5) & (6) & (7) \\
\hline \multirow[t]{2}{*}{$\log (\mathrm{IDE})$} & 0.6153 & -0.0563 & & 0.7112 & -0.0923 & -0.1008 & \\
\hline & $(0.000)^{* * *}$ & $(0.4726)$ & & $(0.000)^{* * *}$ & $(0.3316)$ & $(0.2296)$ & \\
\hline \multirow[t]{2}{*}{$\log (\mathrm{TXI})$} & -1.3298 & & -0.2345 & -0.4600 & -0.0331 & & -0.0978 \\
\hline & $(0.000)^{* * *}$ & & $(0.1620)$ & $(0.2182)$ & $(0.8303)$ & & $(0.4884)$ \\
\hline \multirow[t]{2}{*}{ Log(TCREF) } & -0.5379 & -0.0612 & -0.1065 & -0.8437 & -0.0203 & -0.0116 & -0.1117 \\
\hline & $(0.000)^{* * * *}$ & $(0.5696)$ & $(0.1968)$ & $(0.0010) * * *$ & $(0.8726)$ & $(0.9201)$ & $(0.2090)$ \\
\hline \multirow[t]{2}{*}{$\log (G A)$} & 0.8591 & 0.0758 & 0.1940 & & & & \\
\hline & $(0.000)^{* * *}$ & $(0.3852)$ & $(0.0966) *$ & & & & \\
\hline \multirow[t]{2}{*}{ DPIB Mundo } & & & & -0.0136 & 0.0148 & 0.0140 & 0.0121 \\
\hline & & & & $(0.6707)$ & $(0.2738)$ & $(0.2633)$ & $(0.3552)$ \\
\hline \multirow[t]{2}{*}{$\log (\mathrm{XLTt}-1)$} & & 0.9479 & 0.8674 & & 1.0162 & 1.0241 & 0.9024 \\
\hline & & $(0.0000)^{* * *}$ & $(0.0000)^{* * *}$ & & $(0.0000)^{* * *}$ & $(0.0000)^{* * *}$ & $(0.0000)^{* * *}$ \\
\hline Observações & 21 & 20 & 20 & 20 & 20 & 20 & 20 \\
\hline $\mathrm{R} 2$ & 0.9963 & 0.9975 & 0.9977 & 0.9837 & 0.9975 & 0.9975 & 0.9974 \\
\hline \multirow[t]{2}{*}{ Teste BG LM } & 2.3924 & 12.5942 & 13.1402 & 12.2391 & 13.0320 & 7.2596 & 0.8818 \\
\hline & $(0.3023)$ & $(0.0018)^{* *}$ & $(0.0014)^{* *}$ & $(0.0022) * *$ & $(0.0015)^{* *}$ & $(0.0265)^{* *}$ & $(0.6435)$ \\
\hline \multirow[t]{2}{*}{ Teste de White } & 16.8967 & 19.8294 & 19.9308 & 12.8080 & 18.3667 & 19.0231 & 17.0513 \\
\hline & $(0.2617)$ & $(0.0995)$ & $(0.1323)$ & $(0.5417)$ & $(0.0491)$ & $(0.1224)$ & $(0.2535)$ \\
\hline
\end{tabular}

Fonte: Elaborada pelos autores a partir dos dados da pesquisa.

Nota: Todas as regressões incluem um termo constante e são estimadas por MQO. P-values estão em parênteses (***,**, ${ }^{*}$ significativo a $1 \%, 5 \%$ e $\left.10 \%\right)$.

Passando à análise da Tabela 6, esta apresenta os resultados dos modelos das exportações de média tecnologia. O modelo da coluna (1) apresentou resultados significativos para a maioria das variáveis, à exceção da taxa de câmbio. É importante notar que a variável IDE apresentou um resultado positivo ligeiramente superior ao caso das exportações de baixa tecnologia. Em relação ao resultado não significativo da TCREF, pode-se dizer que, no caso dos setores mais intensivos em tecnologia, o preço não é o fator competitivo mais importante.

As colunas (2) e (3) se referem às estimações, considerando em separado os efeitos do IDE e da TXI, incluindo a variável XMT t-1 para corrigir o problema da autocorrelação. De um lado, as variáveis IDE e TXI deixaram de ser significativas, enquanto a TCREF, o grau de abertura e a variável $X M T_{t-1}$ apresentaram resultados positivos significativos. O efeito da TCREF é o mais baixo, enquanto $X M T_{t-1}$ apresenta o maior coeficiente. Pode-se dizer que a dinâmica das exportações é, em grande parte, explicada pelo desempenho exportador no período anterior; todavia, pode ser que o efeito predominante dessa variável esteja subestimando os coeficientes das demais variáveis. Nas colunas de (4) a (7), os modelos incluem a variável PIB Mundo. O modelo da coluna (4) não é satisfatório, apesar do resultado positivo significativo do IDE, pois a maior parte das variáveis não apresentou resultados significativos. Nas colunas (5) a (7), a inclusão da variável $X M T_{t-1}$ corrige $\mathrm{o}$ 
problema da autocorrelação, mas a variável IDE passa a apresentar um sinal não esperado. Além disso, o PIB Mundo não se mostrou significativo, enquanto a variável $X M T_{t-1}$ apresentou resultados positivos e significativos. Em geral, os resultados encontrados para o modelo das exportações de média tecnologia são frágeis.

Tabela 6 - Exportações de Média Tecnologia - Variável dependente - Logaritmo das exportações de média tecnologia (1985-2005)

\begin{tabular}{|c|c|c|c|c|c|c|c|}
\hline & (1) & (2) & (3) & (4) & (5) & (6) & (7) \\
\hline \multirow[t]{2}{*}{$\log (\mathrm{IDE})$} & 0.6611 & -0.0562 & & 0.8608 & -0.2776 & -0.1731 & \\
\hline & $(0.000)^{* * *}$ & $(0.3013)$ & & $(0.000)^{* * *}$ & $(0.0024)^{* *}$ & $(0.0994)^{*}$ & \\
\hline \multirow[t]{2}{*}{$\log (\mathrm{TXI})$} & -2.1389 & & -0.2059 & 0.2077 & 0.7360 & & 0.4921 \\
\hline & $(0.000)^{* * *}$ & & $(0.2384)$ & $(0.7892)$ & $(0.0015) * *$ & & $(0.0557)^{* *}$ \\
\hline \multirow[t]{2}{*}{ Log(TCREF) } & -0.1711 & 0.1879 & 0.1669 & -0.6247 & 0.2538 & 0.1601 & 0.0588 \\
\hline & $(0.1879)$ & $(0.0445)^{* *}$ & $(0.0585)^{* *}$ & $(0.1751)$ & $(0.0523)^{* *}$ & $(0.3461)$ & $(0.6926)$ \\
\hline \multirow[t]{2}{*}{$\log (\mathrm{GA})$} & 2.0392 & 0.5888 & 0.7188 & & & & \\
\hline & $(0.000)^{* * *}$ & $(0.0000)^{* * *}$ & $(0.0000) * * *$ & & & & \\
\hline \multirow[t]{2}{*}{ DPIB Mundo } & & & & -0.0492 & 0.0054 & 0.0282 & -0.0033 \\
\hline & & & & $(0.4717)$ & $(0.7461)$ & $(0.2111)$ & (0.8828) \\
\hline \multirow[t]{2}{*}{$\log (\mathrm{XLTt}-1)$} & & 0.8728 & 0.8041 & & 1.1642 & 1.1111 & 0.8975 \\
\hline & & $(0.0000)^{* * *}$ & $(0.0000)^{* * *}$ & & $(0.0000)^{* * *}$ & $(0.0000)^{* * *}$ & $(0.0000)^{* * *}$ \\
\hline Observações & 21 & 20 & 20 & 20 & 20 & 20 & 20 \\
\hline $\mathrm{R} 2$ & 0.9955 & 0.9985 & 0.9985 & 0.9553 & 0.9976 & 0.9949 & 0.9952 \\
\hline \multirow[t]{2}{*}{ Teste BG LM } & 6.2965 & 1.2411 & 1.4453 & 12.6515 & 3.2231 & 1.6008 & 5.5467 \\
\hline & $(0.0429) * *$ & $(0.5376)$ & $(0.4855)$ & $(0.0018)^{* *}$ & $(0.1996)$ & $(0.4492)$ & $(0.0625)^{* *}$ \\
\hline \multirow[t]{2}{*}{ Teste de White } & 12.6805 & 10.0668 & 10.3257 & 16.7023 & 12.4756 & 18.9810 & 17.8450 \\
\hline & $(0.5518)$ & $(0.7573)$ & $(0.7380)$ & $(0.2724)$ & $(0.2545)$ & $(0.1657)$ & $(0.2139)$ \\
\hline
\end{tabular}

Fonte: Elaborada pelos autores a partir dos dados da pesquisa.

Nota: Todas as regressões incluem um termo constante e são estimadas por MQO. P-values estão em parênteses $\left(* * * * *\right.$, ${ }^{*}$ significativo a $1 \%, 5 \%$ e $\left.10 \%\right)$.

Por último, a Tabela 7 apresenta os resultados dos modelos das exportações de alta tecnologia. Na coluna (1) é interessante notar que o coeficiente da variável IDE é bastante superior ao dos casos anteriores (1.03), com um nível de significância de 1\%. Por outro lado, como já encontrado nas estimações anteriores, a taxa de investimento apresentou um resultado inesperado, com o sinal invertido, enquanto a taxa de câmbio não se mostrou significativa, o que está relacionado com a importância reduzida dessa variável em setores de alta intensidade tecnológica. Certamente, há uma relação entre o grau de abertura, variável com o maior coeficiente positivo, com a atração de fluxos de capitais estrangeiros e com a promoção das exportações.

O modelo da coluna (2) e (3) excluiu a variável TXI e a variável IDE, respectivamente, e incluiu a variável $X M T_{t-1}$ pelos motivos já expostos. O que se percebe é que, apesar de corrigir o problema da correlação serial, a maior parte 
das variáveis deixa de apresentar resultados significativos, enquanto a variável $X H T_{t-1}$ apresenta os maiores coeficientes positivos e significativos. As colunas de (4) a (7) se referem aos modelos que incluem a variável PIB Mundo, excluindo a variável GA. O setor de alta tecnologia apresentou resultados semelhantes à análise feita para o setor de média tecnologia. Notou-se que, no modelo da coluna (4), apesar do IDE ter apresentado um resultado positivo e significativo, a estimação apresentou correlação serial positiva. Ao incluir então a variável $X H T_{t-1}$, apesar de corrigir o problema, o IDE passa a ter um sinal negativo não esperado, enquanto a maioria das variáveis não apresenta resultados significativos, à exceção da variável $X H T_{t-1}$.

Tabela 7 - Exportações de alta tecnologia - Variável dependente - Logaritmo das exportações de alta tecnologia (1985-2005)

\begin{tabular}{|c|c|c|c|c|c|c|c|}
\hline & (1) & (2) & (3) & (4) & (5) & (6) & (7) \\
\hline \multirow[t]{2}{*}{$\log (\mathrm{IDE})$} & 1.0316 & 0.0837 & & 1.2683 & -0.1509 & -0.1076 & \\
\hline & $(0.0000)^{* * *}$ & $(0.2413)$ & & $(0.0000)^{* * *}$ & $(0.0723)^{*}$ & $(0.2717)$ & \\
\hline \multirow[t]{2}{*}{$\log (\mathrm{TXI})$} & -2.2343 & & 0.1278 & 0.5071 & 0.5493 & & 0.4824 \\
\hline & $(0.0000) * * *$ & & $(0.4983)$ & $(0.5863)$ & $(0.0098) * *$ & & $(0.0270)$ \\
\hline \multirow[t]{2}{*}{ Log(TCREF) } & 0.2483 & 0.1061 & 0.0813 & -0.1945 & 0.0091 & -0.0328 & -0.0082 \\
\hline & $(0.1228)$ & $(0.2648)$ & $(0.3962)$ & $(0.7159)$ & $(0.9333)$ & $(0.8049)$ & $(0.9445)$ \\
\hline \multirow[t]{2}{*}{$\log (\mathrm{GA})$} & 2.4167 & 0.5732 & 0.4470 & & & & \\
\hline & $(0.0000) * * *$ & $(0.0001) * * *$ & $(0.0055) * *$ & & & & \\
\hline \multirow[t]{2}{*}{ DPIB Mundo } & & & & -0.0389 & 0.0121 & 0.0314 & 0.0089 \\
\hline & & & & $(0.6326)$ & $(0.4722)$ & $(0.1097)$ & $(0.6228)$ \\
\hline \multirow[t]{2}{*}{$\log (\mathrm{XLTt}-1)$} & & 0.8043 & 0.8739 & & 1.0197 & 1.0177 & 0.9174 \\
\hline & & $(0.0000) * * *$ & $(0.0000)^{* * *}$ & & $(0.0000)^{* * * *}$ & $(0.0000) * * *$ & $(0.0000)^{* * * *}$ \\
\hline Observações & 21 & 20 & 20 & 20 & 20 & 20 & 20 \\
\hline $\mathrm{R} 2$ & 0.9967 & 0.9992 & 0.9991 & 0.9698 & 0.9989 & 0.9981 & 0.9985 \\
\hline \multirow[t]{2}{*}{ Teste BG LM } & 2.3720 & 3.7689 & 3.0422 & 13.2773 & 3.3068 & 0.1444 & 1.2752 \\
\hline & $(0.3054)$ & $(0.1519)$ & $(0.2185)$ & $(0.0013)^{* * *}$ & $(0.1914)$ & $(0.9304)$ & $(0.5286)$ \\
\hline \multirow[t]{2}{*}{ Teste de White } & 5.2699 & 6.3269 & 5.8271 & 13.5626 & 9.5906 & 7.5422 & 5.9176 \\
\hline & $(0.7284)$ & $(0.6107)$ & $(0.6666)$ & $(0.0939)$ & $(0.4771)$ & $(0.4794)$ & $(0.6565)$ \\
\hline
\end{tabular}

Fonte: Elaborada pelos autores a partir dos dados da pesquisa.

Nota: Todas as regressões incluem um termo constante e são estimadas por MQO. P-values estão em parênteses $\left(* * *, * *,{ }^{*}\right.$ significativo a $1 \%, 5 \%$ e $\left.10 \%\right)$.

Em geral, pode-se dizer que a hipótese testada de efeitos diferenciados do IDE entre os setores de exportação classificados segundo a intensidade tecnológica parece ter se confirmado, com um efeito superior do IDE no caso dos setores mais intensivos em tecnologia. De um lado, os resultados divergem daqueles encontrados por Zhang (2005), em que os efeitos do IDE foram mais fortes nos setores de exportação mais intensivos em trabalho. De outro lado, Alfaro (2003), ao estimar os efeitos do IDE sobre o crescimento econômico, concluiu 
que o IDE que é atraído para os setores de manufaturas versus os setores de primários tem impactos superiores sobre o crescimento. Além disso, o trabalho de Awokuse e $\mathrm{Gu}$ (2007), ao considerar os efeitos do IDE sobre grandes indústrias de exportação (alimentos, bebidas, minerais, químicos, têxteis e maquinários), conclui que os efeitos do IDE nos setores mais intensivos em capital vis-à-vis os setores intensivos em trabalho, é mais eficiente para promover as exportações. No entanto, devem ser consideradas as diferenças quanto à metodologia empregada em tais trabalhos, que não utilizou a análise de séries temporais e realizou estimativas para períodos diferentes. Então, para avançar nessas primeiras conclusões, a próxima seção apresenta a análise de decomposição de variância das exportações chinesas, também desagregando para os setores de baixa, média e alta tecnologia.

\subsection{Análise de Decomposição de Variância das Exportações da China}

A Tabela 8 mostra os resultados para as exportações totais da China, sendo que foram estimados três modelos distintos. Em todos os modelos, a análise de decomposição da variância (ADV) informou que a variável de maior importância para explicar as variações futuras das exportações totais chinesas é a própria dinâmica das exportações (mais de $88 \%$ ).

Tabela 8 - ADV para X - China - Modelos 1 a 3 (1985-2005) - VAR(1)

\begin{tabular}{c|c|c|c|c|c}
\hline \multicolumn{6}{c}{ Modelo I } \\
\hline Período & $\mathrm{X}$ & IDE & TXI & TCREF & GA \\
\hline 1 & 100.00000 & 0.00000 & 0.00000 & 0.00000 & 0.00000 \\
\hline 5 & 96.31879 & 0.370057 & 3.272171 & 0.001599 & 0.037378 \\
\hline 10 & 95.94206 & 1.365665 & 2.629011 & 0.001682 & 0.061583 \\
\hline
\end{tabular}

Modelo 2

\begin{tabular}{c|c|c|c|c|c}
\hline Período & $X$ & IDE & TXI & TCREF & PIBMUNDO \\
\hline 1 & 100.00000 & 0.00000 & 0.00000 & 0.00000 & 0.00000 \\
\hline 5 & 88.91289 & 3.075218 & 1.432561 & 0.670989 & 5.908341 \\
\hline 10 & 88.44914 & 6.028362 & 0.513445 & 0.675777 & 4.333275 \\
\hline
\end{tabular}

Modelo 3

\begin{tabular}{c|c|c|c|c|c}
\hline Período & $\mathrm{X}$ & IDE & TXI & TCREF & PIBUE \\
\hline 1 & 100.00000 & 0.00000 & 0.00000 & 0.00000 & 0.00000 \\
\hline 5 & 92.77826 & 0.589812 & 0.651762 & 0.606102 & 5.374068 \\
\hline 10 & 93.36629 & 2.192639 & 0.094904 & 0.573479 & 3.772692 \\
\hline
\end{tabular}

Fonte: Elaborada pelos autores a partir dos dados da pesquisa. 
No modelo 1 , a variável que apresentou uma contribuição significativa foi a taxa de investimento (DTXI), explicando $2 \%$ da variância de X. O modelo 2 deixa de considerar o grau de abertura e a variável renda externa é incluída, representada pelo PIB Mundial. Com essa nova estimação, a contribuição do IDE se elevou para cerca de $6 \%$, enquanto a contribuição relativa de DTXI e de DTCREF deixa de ser importante, sendo que a variável DPIB Mundo tem a maior contribuição (4\%). Além disso, reduziu a importância da própria dinâmica das exportações na explicação dos movimentos de $(\mathrm{X})$. O modelo 3 inclui como renda externa o PIB da União Europeia. ${ }^{7}$ É possível perceber que a contribuição relativa do IDE diminui em relação ao modelo 2 (2\%), sendo que o PIB UE é a variável mais significativa (3\%). ${ }^{8}$

As tabelas a seguir apresentam os resultados da estimação da ADV para as exportações chinesas agrupadas segundo a intensidade tecnológica, sendo que foram considerados modelos distintos também no caso das exportações setoriais.

A Tabela 9 mostra os resultados para as exportações chinesas de baixa tecnologia. Também no caso das exportações por setor, como será visto no caso das exportações de média e alta tecnologia, os movimentos das exportações (XLT) são explicados pela própria dinâmica das exportações. No modelo $1, a$ principal contribuição relativa é a da taxa de investimento (5\%) e a do grau de abertura (4.7\%), o que é consoante com o desempenho de destaque da China na indústria de têxteis, vestuário e calçados, na qual se tornou o principal exportador de tecidos para os Estados Unidos e de vestuário para o Japão e Canadá, e o segundo maior exportador para a UE (INTER-AMERICAN DEVELOPMENT BANK, 2005), nos anos 2000, após sua entrada na OMC.

A inclusão do PIB da União Europeia (UE) tem a ver com a importância desse mercado no total das exportações chinesas, com destaque para Alemanha com uma participação de $4 \%$.

Conforme a Tabela 12, do Apêndice, estimando ADV para variáveis estacionárias, percebeu-se que a contribuição relativa das variáveis em conjunto nos três modelos estimados é maior, respectivamente, $15 \%, 15 \%$ e $25 \%$, quando comparada às estimações que consideraram variáveis em nível, cuja contribuição é $4 \%, 11,5 \%$ e $6,6 \%$. 
Tabela 9 - ADV para XLT - China - Modelos 1 a 3 (1985-2005) - VAR(1)

\begin{tabular}{c|c|c|c|c|c}
\hline \multicolumn{6}{c}{ Modelo 1 } \\
\hline Período & XLT & IDE & TXI & TCREF & GA \\
\hline 1 & 100.0000 & 0.00000 & 0.00000 & 0.00000 & 0.00000 \\
\hline 5 & 90.35316 & 0.244072 & 4.447627 & 0.041646 & 4.913494 \\
\hline 10 & 89.25929 & 0.370548 & 5.548411 & 0.070117 & 4.751638 \\
\hline
\end{tabular}

Modelo 2

\begin{tabular}{c|c|c|c|c|c}
\hline Período & XLT & IDE & TXI & TCREF & PIBMUNDO \\
\hline 1 & 100.0000 & 0.00000 & 0.00000 & 0.00000 & 0.00000 \\
\hline 5 & 88.54156 & 4.018984 & 0.915977 & 0.109798 & 6.413685 \\
\hline 10 & 84.55798 & 8.378824 & 0.710903 & 0.3708 & 5.981498 \\
\hline
\end{tabular}

Modelo 3

\begin{tabular}{c|c|c|c|c|c}
\hline Período & XLT & IDE & TXI & TCREF & PIBUE \\
\hline 1 & 100.0000 & 0.00000 & 0.00000 & 0.00000 & 0.00000 \\
\hline 5 & 88.61177 & 4.607023 & 1.916002 & 0.202605 & 4.662604 \\
\hline 10 & 84.33946 & 9.251834 & 1.745747 & 0.673247 & 3.989707 \\
\hline
\end{tabular}

Fonte: Elaborada pelos autores a partir dos dados da pesquisa.

O modelo 2 inclui a variável PIB mundial, observou-se, nesse caso, que o IDE passa a explicar cerca de $8 \%$ dos movimentos de XLT; destaca-se também a contribuição do PIB Mundo (5.9\%). O modelo 3 inclui a variável PIB UE, nesse caso, a contribuição conjunta das variáveis consegue explicar 13\% da variância em XLT, sendo que o IDE continua explicando parte importante da variância futura de XLT (9\%).

A Tabela 10 mostra os resultados da ADV para as exportações de média tecnologia. No modelo 1, o IDE se destaca explicando cerca de 12\% da variância futura de XMT, sendo que o conjunto das variáveis explica quase $20 \%$ dos movimentos em XMT. No modelo 2, que inclui a variável PIB mundial, o IDE tem sua importância reduzida, representando cerca de 7\% da variância de XMT, sendo que o PIB mundial não se mostra um bom previsor, com uma influência desprezível. $\mathrm{O}$ modelo 3 apresenta resultados semelhantes em relação às variáveis PIB UE, TXI e TCREF, com uma contribuição pouca significativa sobre XMT. Assim, no caso dos modelos 2 e 3, a contribuição do conjunto das variáveis para explicar movimentos em XMT é menor, cerca de 10\%. Destaca-se apenas a variável IDE que mantém sua importância no modelo (9\%).

A Tabela 11 mostra os resultados da ADV para as exportações de alta tecnologia. Como foi encontrado no caso das exportações de baixa tecnologia, no modelo 1 , os choques derivados da taxa de investimento (TXI) e do grau de abertura (GA) são bons previsores da variância futura de XHT, representando $5.9 \%$ e $2.4 \%$, respectivamente, sendo que a taxa de câmbio (TCREF) e o IDE não têm uma influência importante. Os modelos 2 e 3, que incluem a variável 
renda externa, não se mostram bons previsores dos movimentos de XHT, sendo que a contribuição conjunta das variáveis explica menos de $5 \%$ da variância futura de XHT. ${ }^{9}$

Tabela 10 - ADV para XMT - China - Modelos 1 a 3 (1985-2005) - VAR(1)

Modelo 1

\begin{tabular}{c|c|c|c|c|c}
\hline Período & XMT & IDE & TXI & TCREF & GA \\
\hline 1 & 100.0000 & 0.00000 & 0.00000 & 0.00000 & 0.00000 \\
\hline 5 & 84.92628 & 8.933804 & 2.957251 & 0.530889 & 2.651774 \\
\hline 10 & 82.49096 & 12.6011 & 1.832986 & 0.660895 & 2.41406 \\
\hline
\end{tabular}

Modelo 2

\begin{tabular}{c|c|c|c|c|c}
\hline Período & XMT & IDE & TXI & TCREF & PIBMUNDO \\
\hline 1 & 100.0000 & 0.00000 & 0.00000 & 0.00000 & 0.00000 \\
\hline 5 & 92.94687 & 6.06849 & 0.717738 & 0.13909 & 0.127814 \\
\hline 10 & 89.95725 & 9.223244 & 0.429407 & 0.18839 & 0.20171 \\
\hline
\end{tabular}

Modelo 3

\begin{tabular}{c|c|c|c|c|c}
\hline Período & XMT & IDE & TXI & TCREF & PIBUE \\
\hline 1 & 100.0000 & 0.00000 & 0.00000 & 0.00000 & 0.00000 \\
\hline 5 & 92.30198 & 6.799122 & 0.658788 & 0.238252 & 0.001854 \\
\hline 10 & 89.32843 & 9.984377 & 0.378875 & 0.296186 & 0.012134 \\
\hline
\end{tabular}

Fonte: Elaborada pelos autores a partir dos dados da pesquisa.

9 Como no caso das exportações agregadas, também para as exportações setoriais, percebeu-se que a contribuição relativa dos modelos 1,2 e 3, testando variáveis estacionárias, é maior, igual a 19\%, $15 \%$ e $10,8 \%$, respectivamente, quando comparada aos modelos com variáveis em nível, em que essa contribuição foi de $12,5 \%, 9,5 \%$ e 9,7\%, respectivamente. Ver Tabela 12, do Apêndice. 
Tabela 11 - ADV para XHT - China - Modelos 1 a 3 (1985-2005) - VAR(1)

\begin{tabular}{c|c|c|c|c|c}
\hline \multicolumn{6}{c}{ Modelo 1 } \\
\hline Período & XHT & IDE & TXI & TCREF & GA \\
\hline 1 & 100 & 0 & 0 & 0 & 0 \\
\hline 5 & 90.71999 & 0.210376 & 6.290813 & 0.047212 & 2.731609 \\
\hline 10 & 90.73284 & 0.854258 & 5.956452 & 0.047685 & 2.408763 \\
\hline
\end{tabular}

Modelo 2

\begin{tabular}{c|c|c|c|c|c}
\hline Período & XHT & IDE & TXI & TCREF & PIBMUNDO \\
\hline 1 & 100 & 0 & 0 & 0 & 0 \\
\hline 5 & 96.69667 & 0.062204 & 2.561457 & 0.035902 & 0.643767 \\
\hline 10 & 96.86876 & 0.735153 & 1.853454 & 0.048893 & 0.493742 \\
\hline
\end{tabular}

Modelo 3

\begin{tabular}{c|c|c|c|c|c}
\hline Período & XHT & IDE & TXI & TCREF & PIBUE \\
\hline 1 & 100 & 0 & 0 & 0 & 0 \\
\hline 5 & 96.49678 & 0.092859 & 1.541955 & 0.139869 & 1.728534 \\
\hline 10 & 96.99522 & 0.78516 & 0.80675 & 0.137923 & 1.274945 \\
\hline
\end{tabular}

Fonte: Elaborada pelos autores a partir dos dados da pesquisa.

Comparando os modelos do VAR para as exportações de baixa, média e alta tecnologia, deve-se destacar que a contribuição relativa da variável (IDE) apresentou uma importância maior nos casos das exportações de média e baixa tecnologia, apresentando uma contribuição desprezível no caso dos setores de alta tecnologia. No caso das exportações de média tecnologia, essa contribuição atingiu até $12 \%$.

Em relação às demais variáveis, o grau de abertura revelou ter uma contribuição importante na explicação da variância das exportações dos três grupos, bem como a taxa de investimento, que teve um destaque ainda maior (à exceção do caso das exportações de média tecnologia). Pode se especular que a variável TXI (que é a razão entre a formação bruta de capital fixo e o PIB) estaria captando o efeito do IDE. Deve-se destacar que os resultados encontrados quanto à importância elevada da taxa de investimento é consoante com o desempenho econômico da China, que apresentou um crescimento do PIB, em 2007, de 11.4\%, o melhor nível atingido nos últimos 13 anos. Além disso, os fluxos de IDE contribuíram para geração de divisas ao promover as exportações, sendo importante componente do crescimento. Por último, nos modelos que consideram a contribuição relativa da renda externa, notou-se que os choques do PIB mundial e da União Europeia não são bons previsores dos movimentos das exportações, à exceção do caso das exportações de baixa tecnologia, em que o PIB Mundo representou 5\% da variância de XLT. 


\section{Considerações Finais}

A China constitui uma importante experiência de economia em desenvolvimento, pois seu processo de abertura, de caráter gradual, com a definição de políticas e estratégias de crescimento e desenvolvimento, levou a um desempenho econômico surpreendente nos últimos vinte anos. Um dos eixos do processo de abertura econômica diz respeito ao setor externo da economia, com a liberalização comercial e a entrada significativa de investimentos diretos externos (IDE). Além das mudanças em termos quantitativos, foi observada também uma melhora qualitativa na pauta de exportações da China.

A análise de regressão e a estimação da VAR, por meio do instrumento de decomposição da variância dos erros, sugerem que a variável IDE é importante para explicar as exportações da China. No caso do primeiro método e considerando os modelos que melhor se ajustaram, o IDE apresentou um coeficiente com sinal esperado e significativo a $1 \%$. Em termos setoriais, foram encontrados resultados interessantes considerando o primeiro modelo: o coeficiente obtido para o IDE foi de 0,61; 0,66 e 1,03 no caso das exportações de baixa, média e alta-tecnologia, respectivamente. Pode-se dizer que a importância do IDE se tornou superior à medida que o conteúdo tecnológico das exportações aumentou. Outras variáveis explicativas utilizadas na análise de regressão apresentaram resultados importantes: o grau de abertura e as próprias exportações defasadas no tempo obtiveram coeficientes, em geral, com os sinais esperados e significativos.

No segundo método, o IDE apresentou uma contribuição relativa que variou de $2.1 \%$ a $6 \%$, considerando os três modelos da análise para as exportações totais. No caso da ADV setorial, tanto na estimação para as exportações de média, quanto de baixa tecnologia, o IDE obteve a segunda maior contribuição relativa entre as variáveis consideradas comparando-se os três modelos estimados, sendo igual a $12 \%$ e $9 \%$, respectivamente. O mesmo não é observado no caso das exportações de alta tecnologia, cuja contribuição relativa do IDE foi desprezível (menor do que 1\%). De maneira geral, destaca-se a própria dinâmica das exportações como a variável mais importante para explicar os movimentos das exportações.

O trabalho envolveu, em sua parte empírica, importantes limitações relacionadas à indisponibilidade de dados. A construção das séries históricas das variáveis que foram utilizadas nas estimações esteve limitada pela falta de dados de exportação setorial para a China em períodos anteriores a 1985 dessa maneira, foi considerado um período curto de tempo (1985-2005), significando um baixo número de observações, já que a frequência dos dados é anual. Além disso, ao considerar os impactos do IDE em termos dos setores de exportação (baixa, média e alta tecnologia), não foi possível utilizar variáveis explicativas em nível setorial, de maneira que convergissem aos setores de exportação. Portanto, algumas questões permanecem em aberto e se colocam como agenda futura de pesquisa: (i) a análise de séries temporais não parece ser o melhor instrumento para verificar a hipótese proposta pelo trabalho, que é relacionar a entrada de 
capitais estrangeiros com as mudanças na composição da pauta de exportações em direção aos setores mais intensivos em tecnologia. Nesse sentido, deve ser considerado um instrumento econométrico diverso para superar os limites impostos pelo baixo número de observações e (ii) deve ser feito um esforço de compatibilização dos dados setoriais de exportação com as variáveis explicativas que, geralmente, possuem um nível de desagregação inferior.

\section{Referências}

ALFARO, L. Foreign direct investment and economic growth: does the sector matter? Harvard Business School, abr. 2003.

ASIAN DEVELOPMENT OUTLOOK. Foreign direct investment in developing Asia. 2004.

AWOKUSE, T.; GU, W. The contribution of foreign direct investment to China's export performance: evidence from disaggregated sectors. Delaware, USA: University of Delaware, jun. 2007.

BRANSLETTER, L.; LARDY, N. China's embrace of globalization., Cambridge, MA: National Bureau of Economic Research, jul. 2006. (NBER Working Paper, n. 12373).

EICHENGREEN, B.; RHEE, Y.; TONG, H. The impact of China on the exports of other Asian countries. Cambridge, MA: National Bureau of Economic Research, set. 2004. (NBER Working Paper, n. 10768).

ENDERS, W. Applied econometric time series. 2. ed. New Jersey: John Wiley E Sons, 2004. (Wiley Series in Probability and Statistics).

HAUSMANN, R.; RODRIK, D. Economic development as self-discovery. Journal of Development Economics, v. 72, n. 2, p. 603-633, 2003.

HSIAO, F. S. T.; HSIAO, M. W. FDI, exports, and GDP in East and Southeast Asia: panel data versus time-series causality analyses. Journal of Asian Economics, v. 17, n. 6, p. 1082-1106, dez. 2006.

INTER-AMERICAN DEVELOPMENT BANK - IDB. The emergence of China: opportunities and challenges for Latin America and the Caribbean, 2005.

JOHNSON, A. FDI and exports: the case of the high perfoming East Asian economies. jan. 2006. (CESIS Eletronic Working Paper Series, n. 57).

LALL, S. Export performance, technological upgrading and foreign direct investment strategies in the Asian newly industrializing economies. Santiago, Chile: Cepal, out. 2000.

LIU, X.; WANG, C.; WEI, Y. Causal links between foreign direct investment and trade in China. China Economic Review, v. 12, n. 2-3, p. 190-202, 2001.

ORGANIZAÇÃO MUNDIAL DO COMÉRCIO. World Trade Policy Review. China, 2006. 
RODRIK, D. What's so especial about China's exports? Cambridge, MA: National Bureau of Economic Research, jan. 2006. (NBER Working Paper, n. 11947).

RUMBAUGH, T.; BLANCHER, N. China: International Trade and WTO Accession. Washington, DC: IMF, mar. 2004. (IMF Working Paper).

ZHANG, K. H. How does FDI affect a host country`s export performance? The case of China. In: INTERNATIONAL CONFERENCE WTO, CHINA AND THE ASIAN ECONOMIES, 3., 2005, Xian, China. Proceedings..., Xian, China: Xian Jiatong University, jun. 2005.

ZHANG, K. H.; SONG, S. Promoting exports: the role of inward FDI in China. China Economic Review, v. 11, n. 4, p. 385-396, 2000.

ZHANG, Q.; FELMINGHAN, B. The relationship between inward direct investment and China's provincial export trade. China Economic Review, v. 12, n. 1, p. 82-99, 2001.

ZUCOLOTO, G.; CASSIOLATO, J. E. Globalização das atividades de pesquisa e desenvolvimento e seus impactos em Brasil, Rússia, Índia, China e África do Sul. In:

ENCONTRO NACIONAL DE ECONOMIA POLÍTICA, 11., 2006, Vitória, ES. Anais... Vitória, ES: SEP, 2006. 1 CD-ROM.

\section{Apêndice}

Tabela 12 - Comparação entre as estimações da ADV para modelos com variáveis em nível e estacionárias

\begin{tabular}{|c|c|c|c|c|}
\hline \multicolumn{5}{|c|}{ Somatório para Variáveis em Nivel: Diferentes Modelos } \\
\hline Soma \% X & $\begin{array}{c}\text { Soma \% } \\
\text { XHT }\end{array}$ & $\begin{array}{c}\text { Soma \% } \\
\text { XMT }\end{array}$ & $\begin{array}{c}\text { Soma \% } \\
\text { XLT }\end{array}$ & Média simples \\
\hline $\mathrm{X} / \mathrm{M} 1$ & XHT / M1 & $\mathrm{XMT} / \mathrm{M} 1$ & $\mathrm{XLT} / \mathrm{M} 1$ & $(\mathrm{XHT}+\mathrm{XMT}+\mathrm{XLT}) / \mathrm{M} 1$ \\
\hline 4,06 & 9,27 & 17,51 & 10,74 & 12,51 \\
\hline $\mathrm{X} / \mathrm{M} 2$ & $\mathrm{XHT} / \mathrm{M} 2$ & $\mathrm{XMT} / \mathrm{M} 2$ & $\mathrm{XLT} / \mathrm{M} 2$ & $(\mathrm{XHT}+\mathrm{XMT}+\mathrm{XLT}) / \mathrm{M} 2$ \\
\hline 11,55 & 3,13 & 10,04 & 15,44 & 9,54 \\
\hline $\mathrm{X} / \mathrm{M} 3$ & $\mathrm{XHT} / \mathrm{M} 3$ & $\mathrm{XMT} / \mathrm{M} 3$ & $\mathrm{XLT} / \mathrm{M} 3$ & $(\mathrm{XHT}+\mathrm{XMT}+\mathrm{XLT}) / \mathrm{M} 3$ \\
\hline 6,63 & 3,00 & 10,67 & 15,66 & 9,78 \\
\hline \multicolumn{5}{|c|}{ Somatório para Variáveis Estacionárias: Diferentes Modelos } \\
\hline $\begin{array}{c}\text { Soma \% } \\
\text { DDX }\end{array}$ & $\begin{array}{l}\text { Soma \% } \\
\text { DDXHT }\end{array}$ & $\begin{array}{c}\text { Soma \% } \\
\text { DXMT }\end{array}$ & $\begin{array}{c}\text { Soma \% } \\
\text { DXLT }\end{array}$ & Média simples \\
\hline $\mathrm{DDX} / \mathrm{M} 1$ & DDXHT / M1 & DXMT / M1 & $\mathrm{DXLT} / \mathrm{M1}$ & $(\mathrm{DDXHT}+\mathrm{DXMT}+\mathrm{DXLT}) / \mathrm{M} 1$ \\
\hline 15,25 & 18,90 & 25,42 & 13,05 & 19,12 \\
\hline $\mathrm{DDX} / \mathrm{M} 2$ & DDXHT / M2 & DXMT / M2 & DXLT / M2 & $(\mathrm{DDXHT}+\mathrm{DXMT}+\mathrm{DXLT}) / \mathrm{M} 2$ \\
\hline 15,26 & 17,44 & 17,38 & 10,99 & 15,27 \\
\hline $\mathrm{DDX} / \mathrm{M} 3$ & $\mathrm{DDXHT} / \mathrm{M} 3$ & $\mathrm{DXMT} / \mathrm{M} 3$ & $\mathrm{DXLT} / \mathrm{M} 3$ & $(\mathrm{DDXHT}+\mathrm{DXMT}+\mathrm{DXLT}) / \mathrm{M} 3$ \\
\hline 25,56 & 11,32 & 12,68 & 8,49 & 10,83 \\
\hline
\end{tabular}

Fonte: Elaborada pelos autores a partir dos dados da pesquisa.

Recebido em: 05/04/2010. Aceito em: 08/04/2011. 